\title{
ЗАИМСТВОВАНИЕ ГРАММАТИЧЕСКИХ ФОРМ В АНГЛИЙСКОМ ЯЗЫКЕ (ПО ДАННЫМ ФОРМ ЧИСЛА)
}

\author{
Маматкулова Ш.Джс. \\ Кандидат филологических наук. доиент \\ Самаркандский государственный архитектурно - строительный институт. \\ Узбекистан.
}

\begin{abstract}
Аннотация. В данной статье рассматривается роль и значение заимствованные слова, который часто сохраняют свое множественное число в том форме в какой они стояли в языке, из которого были заимствованы. Из сказанного видно, какой разнобой царит в образовании множественного числа этой группы существительных Annotation. This article is about borrowing words which except plural form of foreign numbers they can have usual English plural forms too. Some of them have got only plural form, the others have only one form for both numders.

We often come across them in novels and scientific literature. Many plural forms of English language have remained their singular forms and that is why they use in any style.

Ключевые слова: заимствованных слов, склонению, материал, стандартный, правила

Keywords: loanwords, declension, material, standard, rules
\end{abstract}

Заимствованные слова очень часто сохраняют свое множественное число в том форме, в какой они стояли в языке, из которого были заимствованы. Некоторые из заимствованных слов, кроме формы иностранного множественного числа, могут иметь и обычную форму английского множественного числа. Другие имеют только форму множественного числа, у третьих есть одна форма для обоих чисел. Довольно большое количество этих существительных чаще имеют английскую форму множественного числа. Из сказанного видно, какой разнобой царит в образовании множественного числа этой группы существительных. Поскольку многие из них довольно часто встречаются и в художественной, и в научной литературе, представляется необходимым привести формирование множественного числа этой группы существительных в какую-то более или менее стройную систему.

Авторы классических грамматик (Jespersen - 1961 - 1965;Kruisinga - 1932; Poutsma - 1914) останавливаются довольно подробно на образовании множественного числа иностранных слов; особенно Есперсен в ModernEnglishGrammar ( orHistoricalPrinciples). Все авторы, кроме Керма (1960) (у которого не удалось обнаружить раздела, посвященного заимствованным формам множественного числа), делят все иностранные слова на несколько групп по определенным закономерностям в образовании множественного числа. Но часто в одну и те же группу попадают существительные, подчиняющиеся разным закономерностям.

Так, у Есперсена genus - genera, dogma - dogmata, stamen - stamina стоят в одной группе, когда было бы очень удобно и более понятно разделить их на разные группы. Поутсма строит закономерности образования множественного числа (например, латинских заимствований) на их принадлежность к тому или иному латинскому склонению. Он даёт много интересных сведений и глубоких замечаний, но воспользоваться этим практически довольно трудно. Кроме того, примеры Есперсена и Поутсмы архаичны (Мильтон, Шекспир и даже Чocep).

Далее по данным различных словарей предлагается определить свод правил, которые, возможно, облегчат усвоение этого объемистого материала. При этом используются цитатные подтверждения заимствований из таких словарей, как A Concise Dictionary, of English Idioms - 1985; A supplement to the Oxford English Dictionary - 1972; Longman Dictionary of Contemporary English - 1978 и другие.

Латинские заимствования Sg. - us; Pl. - i (э): nucleis - ядро - nuclei; termonus - конечнаяостановка - termini; focus -центр - foci: cactus - cacti;stimulus - стимул - stimul: Finally we were shown to the cell of a long corridor. It was like a terminus of a bad dream. (Miller. 17-19). It was like the Union of two magnets, of their dull grey termini; the ever searching part had at last come together (Miller, 70

Ряд слов из этой группы может иметь стандартные формы знаком отмечены слова, которые могут иметь также стандартные формы множественного числа:

Bonus, minus, campus, virus, ignoramus, status, impetus, prospectus, foetus.

The fact that flue is caused by numerous different viruses makes it hard to combat $(1 ; 179-180)$.

Латинские заимствования: Sg. - a; Pl. - ae (i:) «antenna - антенна, щупальца - antennae: formula - формула formulae; alga - морская водоросль - algae; vertebra - позвоночник - vertebrae; alumna - бывшая ученица - alumnae.

We shall fell deeply the honors of having an honorary alumna of old frasmus (S.Lewis,Ann Vickers, 38). She had to go out and address. Dinners of the League or the alumnae of the Phi Fan Sorority of Point Royal (S.Lewis).

ZHe следует смешивать эту группу с существительными на -a, имеющих стандартные формы множественного числа: visa, area, spa, idea, ballerina, rickshaw, insomnia, arena,

enigma, villa, aroma, panorama, etc. 
According to the dates on the visas the couple had sailed six weeks before from Halifax (Maigret 73-74).

Латинские заимствования; Sg. Um; Pl. - adatum - данная величина - data; data - пласт - strata; memorandum памятная записка - memoranda;sanatorium - санаторий - sanatoria; medium - средство, середина - media; serum сыворотка - sera

There was no kind of hint, sketch or memorandum of any testamentary intention whatever (D).Last night the laboratory was broken into, and memoranda were stolen (Chr. Big. 50).

Многие слова на - um имеют только стандартные формы: geranium, museum, chrysanthemum, pendulum, album, etc.

Латинские заимствования: Sg. - ix, ex; Pl. - ices; apex - вершина - apices; index - указатель - indices; appendix аппендикс, приложение - appendices $(2 ; 121-122)$.

At the end of the book there was an appendix (J.K.Jerome, There Men in a Bumull, 59). The Oxford Chekhov is an important undertaking. The notes are good, the appendices on the text and on the composition of the play informed and interesting (Specator).

Греческие заимствования: Sg. - is; Pl - es [i:z] basis - базис - bases; crisis - кризис - crisis; analysis - анализ analyses - оазис - oases; axis - ось - axes; hypotheses; parenthesis - вводное слово - parenthesis; paralysis - паралич paralyses.

She had no power at this crisis to resists (L.W.388).

I stood by him in his four great crises (Sourse,360). The Concise Oxford Dictionary of Current English, 1983, c.351352).

Эта группа самая устойчивая из всех групп существительных с заимствованной формой числа, так как в ней нет стандартных параллельных форм. Она охватывает довольно большое количество общеупотребитеьных и специальных терминов, особенно медицинских. Таким образом, это не исключение, а правило. Эту группу слов целесообразно включить в элементарные грамматические пособия.

Смешние может возникнуть при образований единственного числа от множественного, поскольку написание окончания -еs может быть понятно как стандартное. Во множественном числе появляются омографы: ax (e) топор - axes [oeksi:z], axis - ось - axes [oe], base - база - bases [beisiz], basis - базис - bases[beisi:z], ellips -эллипс, овал - ellipses [Ilipsiz], ellipsis - эллипс, пропуск - ellipses [Ilipsi:z] [3,102].

Овал - ellipses [I'lipsiz], ellipses [I'lipsi:z] [3;].

На этих омографах построена игра слов.

"You see the earth takes twenty-four hours to turn round on it's axis".

"Talking of axes, "said the Duchess", "chop off her head".(Alice,98).

Греческие заимствования: Sg - on; Pl - a phenomenon - явления - phenomena, “criterion - критерий - criteria, "automation - автомат - automata.

He was a phenomenon to her, not a human being: son of creature, greedy (LW.464). As men, personalities they were just accidents, sporadio, little unimportant phenomena (LW 260). (Starnes de with T. and Noyes G.E., 1946, 111- 112).

Наиболее употребительными являются вышеперечисленные три слова. Поэтому их легко запомнить и отграничивать от многочисленных слов на - оn, имеющих стандартную форму множественного числа: comparison, lesson, unison, reason, jettison, mason, etc. Другие, более редкие слова этой группы: ephemeron, parhelion, ophelion, amphibian.

Греческие заимствования: $\mathrm{Sg}$ - a; Pl - ata, “dogma - догма - dogmata, "stigma - пятно - stigmata.

Эта форма множественного числа употребляется очень редко даже в научном стиле. Преимущественно она заменяется стандартной

Итальянские заимствования: Sg - o; Pl - I [ I: ]: “ tempo - темп, ритм - tempi; “concerto - концерт, музпроизведение - concerti.

Большинство итальянских заимствований связано с музыкальным искусством. Чаще всего они заменяются стандартными формами множественного числа [1; 191-192].

Французские заимствования: Sg -s, -x; (не произносится); Pl - s, x [z] (произносится) corps - армейский корпус - corps; pas' - шаг в танце - pas; chamois - серна - chamois; rendezvous; chassis - шасси - chassis; pincenez - пенсне pince-nez.

Many uses will be found if we gather a corps of middlemen ( R-s, 80). It isn't his job to worry about. Such trifles as battalions, let alone individual lives. Why, hethinksinArmycorps (Aldington).

Это живой способ образования множественного числа. Его следует обязательно сообщать изучающим английский язык, конечно, на высшей ступени обучения, так как он

охватывает редко употребительные слова. Незнание особенностей этих слов может вызвать досадные ошибки при чтении и письме.

The first real wind of the adventure fills was fairly launched on a hectic life of our gay sails as we near the rendezvous parties, rendezvous night-clubs and strange meeting of all kinds (Aldington) (N.G.). (A.S.Hornby,1965, c.141-142).

10. Французские заимствования: Sg - eau [ : ], eu [ju: ], ou [u:]; Pl - eaux [:z], eux [ju:z], oux [u:z]; "bureau контора, конторка - bureaux, "adieu - прощание - adieux. 
It was still on her mind when I bade adieu (D.D.) Presently Abbershaw, realizing hat he wished to be alone, made his adieux and went off. (A. Allingham, 166).

Это форма множественного числа встречается очень редко, даже в исключительных случаях для придания тексту ярко национального колорита. Чаще встречается стандартная форма.

He descended into his boat, followed by the continual adieux of Don Benito. (Melville, 77).

К этому же типу обычно относяти portmanteau, chateau, plateau, trousseau.

Но чаще они принимают стандартную форму множественного числа.

The portmanteaus and carpet - bags have been stowed away (D.Pick, 384)

Andianapoinimerina was the first to unify by conquest the people of this high plateaus.)

Многие русские заимствования с - еи никогда не принимают - х, например, milien, purlieu.

There were other, more significant changes which also had their origin here in the purlieus of the Bronx (Miller, 199).

По мере того, как иностранные слова ассимилируются английским языком, они приобретают стандартную форму множественного числа: fortula - fortulas, focus - focuses, memorandum(s), dogma(s), bandit(s), beau(s), cherub(s).

Иногда форма множественного числа переосмысляется в форму единственного числа и от неё образуется множественное число: data - datas.

Процесс аналогизации давно уже идет в английском языке. В настоящий период есть тенденция использовать две формы (иностранную и стандартную) для семантической дифференциации, например:

Index - indices показатель степени в математике

Appendix - appendices аппендикс в кишечнике

Bureau - bureaux конторы

- bureaus

письменные столы

Genius - genii духи

- geniuses гении

Однако эти различия иногда нарушаются. Из выщеперечисленных 10 групп наиболее частотны 1, 3, 5. Они чаще встречаются и в тексте, и в словаре, поскольку охватывают больше по сравнению с другими группами количество слов. Употреблен иностранных слов с заимствованной формой множественного числа придает тексту научный стилев оттенок особенно часто в периодике, публицистической и художественной литературе.

The most penetrating analysis of an act of speech is described in "behaviourist" terms, as a sequence of stimuli responses (Ullman). Like cows, hippopotami are dependent on minute microorganisms which life in their stomachs digestion of heir plant food (The Times).

Научный стиль изобилует иностранными терминами, которые обычно имеют форму числа, характерную именительного падежа тех языков, откуда они были заимствованы. Заимствованных форм множественного числа имеет официально-деловой и канцелярский характер.

The cleark's office of Messrs. Dodson and Fogg was a dark mouldy, earthy smelling room... (D.Pick, 269). It's a piece of fadric, Mesdames, as the king of heaven himself wouldn't mind to put down in his parlour).

Иностранные формы множественного числа употребляются как стилистическое средство передального колорита места, в котором происходят события.

A group of people were standing guarded by carabinieri (Hemingway).

Иногда иностранные формы употребляются в поэзии и высокопарной прозе, в рафинированном и в разном языке.

Narcissi, the fairest of then all

Gaze on their eyes in the steam's recess,

They die of their own dear loviness (Shelley).

Многие иностранные формы множественного числа остаются единственными, и поэтому они употребляются в любом стиле.

The marries, if the attemps to live an ordinary life, the foci of infection may very well light up (251).

Стилистическая ограниченность этого способа образования числа,его явно антидемократический тип не мог не послужить основой для каламбуров, шуток, эпиграмм.

В американском студенческом сленге есть псевдонаучные модели: grimace -grimiwaitress waitricompasscompi [5; 783].

\section{LITERATURE}

1. News M. The compact Edition of the Oxford English Dictionary. 1971

2. The Concise Oxford Dictionary of Current English. 1956

3. Webster`s Seventh New Collegiate Dictionary/ 1961

4. The Shorter Oxford Dictionary. 1965

5. American Spech. Vol.I. 1966. 
This article devotes to the borrowings of grammatical forms in English language (according to the facts of forms) in belles- letters and scientific literature.

\section{ЛИТЕРАТУРА}

1. Аракин В.Д. Сравнительная типология английского и русского языков. Л., 1979.

2. Ахманова О.С. Словарь лингвистических терминов. М.,1966.

3. Багдасарян В.Р. Лексические средства выражения неопределенной количественности в современном английском языке. Автореф. канд. дисс. М., 1987.

4. Маматкулова Ш.Дж. Сопоставительный анализ квантификации окружающего мира в таджикском и английском языках. Канд. дисс. Санкт-Петербург, 1996

5. Semiotics and language: An analytical dictionary. Bloomington, 1982.

6. Webster"s third new International dictionary of the English language. London, 1981. 